\title{
Reading and literacy skills among children in the early school years.
}

\begin{abstract}
Early identification of children most at risk of reading failure is central to the prevention of illiteracy. Therefore the earliest time frame for identification should be determined. Reading is related to communication and literacy. Prominent researchers in the field asserted that, and supported by empirical evidences, early school years is the critical time for early identification and prevention (Torgesen, 1998). This study focuses on Year 1 and Year 4 primary school children utilizing the descriptive correlational method. It was carried out on 344 primary school pupils of which 168 were from Year 1 and 176 were Year 4 pupils. The pupils in the sample were academically weak who underwent screening and diagnostic tests. Findings showed a significant number had difficulty in reading skills. Reading is basic in understanding information and it is related to overall learning in general and Year 1 pupils did have problems in literacy skills where $33.8 \%$ were unable to read and write, As for Year 4 pupils, there was a slight drop in reading skills as compared to the pupils in Year 1. This was perhaps due to the fact that the problems encountered were more difficult. However, pertinently, it was found that those specific areas of weaknesses in other learning subjects (mathematics and languages) were related to reading and literacy skills. The implications are these pupils should be given the diagnostic tests as early as possible(pre school) by the teachers so that intervention programs could be carried out.
\end{abstract}

Keyword: Communication skills; Literacy skills; Early school years. 